\title{
El retorno de la imaginación
}

\author{
Rafael Arce / Universidad Nacional del Litoral - CONICET / rafael.arce@conicet.gov.ar \\ - Soledad Nívoli / Universidad Nacional de Rosario / lanivo@yahoo.com.ar
}

\section{Resumen}

La imaginación como categoría estética ha sido soslayada por el pensamiento del siglo xx. Esta marginación tiene su origen en la separación moderna de la ciencia estricta, la especulación filosófica y la «fantasía»: es decir, en el establecimiento de lo que puede ser conocido de modo verdadero y lo que cae del lado de la ficción, la falsedad y el error. Sin embargo, estaríamos asistiendo, en las últimas décadas, a un retorno de la problemática, junto con la recuperación de la categoría de experiencia, desplazadas en la segunda mitad del siglo xx de los estudios estéticos y literarios como consecuencia de la centralidad del problema del lenguaje y del texto.

Palabras clave: imaginación - experiencia •

conocimiento $\cdot$ percepción

\begin{abstract}
Imagination as an aesthetic category has not been taken into account by the different currents of thought during the 2oth century. This marginalization is due to the modern separation between «hard sciences», philosophical speculation and "phantasy»: i.e., by separating that which can be apprehended in its true condition from that which can be considered on the opposite side, fiction, falsehood and error. However, in the last decades we have been assisting a problematical comeback (of the aesthetical category of imagination), alongside with the category of experience, set aside during the second half of the 2oth century in aesthetic and literary studies as a consequence of the priority attention given to language and text.
\end{abstract}

Key words: imagination $\cdot$ experience $\cdot$ knowledge $\cdot$ perception

«La imaginación al poder» fue el grafiti más célebre pintado durante las manifestaciones del Mayo Francés. ¿¿A qué se debió su perduración? Quizás a que el poder aludido era indefectiblemente el político, y la política, sea como fuere que la definamos, implica una consideración de la realidad concreta, empírica, material. Que la imaginación tome el poder político suena a desafío porque se trataría de dos elementos, en principio, incompatibles: un sentido común, todavía pregnan- 
te, opone imaginación a realidad de modo tajante. Sin embargo, la expresión de los estudiantes del 68 devolvía a la imaginación su potencia de transformación: para inventar un mundo nuevo, había que primero destruir el dado; y para hacer la revolución, había que primero imaginarla.

En la Francia de finales de los sesenta, la expresión era también un axioma complementario de «Las estructuras a la calle». En efecto, el estructuralismo se había vuelto hegemónico como modelo de las ciencias sociales. El análisis del orden simbólico había marginado la consideración del registro imaginario. ¿Qué lugar podía tener la imaginación cuando el hombre, el arte, la cultura y la sociedad se estudiaban buscando la estructura subyacente, incluso la estructura de toda estructura? Lo imaginario no era sólo lo narcisista especular. Rechazado por la política (la revolución, finalmente, fue la experiencia de una utopía, es decir, de una imposibilidad), lo imaginario sólo podía quedar del lado de la ideología, entendida como falsa conciencia: los «imaginarios sociales», esa mitología moderna que había que desenmascarar. Imaginación, en definitiva, era sinónimo de irrealidad y la pasión del siglo habría sido, contrariamente, la pasión de lo real (Badiou:69-8I).

Para Agamben, asociar imaginación con irrealidad es la consecuencia de la constitución (y la separación) moderna de la ciencia y la filosofía. Para el pensamiento antiguo y el medieval, por el contrario, la imaginación cumplía un papel mediador entre intelecto y sensibilidad. En efecto, dice Platón:

En consecuencia, así como el discurso era verdadero y falso, y se mostró que, en él, el razonamiento es el diálogo del alma consigo misma, que el pensamiento es el resultado final del razonamiento, y que llamamos «imaginar» a una mezcla de sensación y de pensamiento... (264aio-b5)

Platón no se refiere aquí a la imaginación (el término utilizado es fantasía) como capacidad de generar imágenes, sino más bien como facultad de juzgar a partir de una percepción: imaginar es un pensar que depende de la sensación y, en cierto modo, una sensación que depende del pensamiento. No obstante, ya aparece la imaginación como una facultad que se sitúa entre pensamiento y sensibilidad. Y a pesar de que en otros diálogos, como el Teeteto, imaginación e imaginario tienen una connotación de falsedad (por lo que es algo que cae fuera del conocimiento), en el Sofista la imaginación se interroga como un momento posible del conocimiento y, por lo tanto, de la ciencia.

En la tercera parte de Acerca del alma, Aristóteles se esfuerza por distinguir imaginación de pensamiento y de sensación. Allí da una fórmula que se volverá célebre en el pensamiento medieval (tal cual nos lo recuerda Agamben: nibil potest homo intelligere sine phantasmate, "nada puede pensarse sin imaginación»): «Es cierto que de no haber sensación no hay imaginación y sin ésta no es posible la actividad de enjuiciar» (427bi6-17). Esta fórmula jerarquiza la imaginación como parte de la actividad cognoscente. Sin embargo, el esfuerzo de Aristóteles es defi- 
nir la imaginación, separarla del pensamiento y de la sensación, entre las cuales se situaba como mediadora en el fragmento platónico. Y al separarla, la imaginación cae de nuevo en el orden de lo falso: la sensación es siempre verdadera, pero una imagen puede ser falsa, al confundir el juicio que la utiliza como apoyo. Por lo tanto, la imaginación no puede entrar en el ámbito del intelecto y de la ciencia: queda por ver si es posible que su concepto sea absorbido por el de opinión (doxa), con lo cual nos acercamos de nuevo a la noción platónica, puesto que juzgar según la sensación sería una clase delopinar. El argumento de Aristóteles es tan simple como sorprendente: lo que distingue al hombre del animal es el pensamiento, por lo que un animal posee no sólo sensación sino también, quizás, imaginación:

Ahora bien, la opinión va siempre acompañada de convicción (...) y en ninguna bestia se da convicción a pesar de que muchas de ellas posean imaginación. Además, toda opinión implica convicción, la convicción implica haber sido persuadido y la persuasión implica la palabra. Y si bien algunas bestias poseen imaginación, sin embargo no poseen palabra. Queda, pues, evidenciado que la imaginación no es ni una opinión acompañada de una sensación, ni una opinión producida por una sensación, ni el conjunto de opinión y sensación. (428a20-26)

Para Aristóteles, lo propio de la imaginación es tener un cierto vínculo, que habría que desentrañar, con la sensación. En efecto, aquí está anticipada una preocupación moderna que intentará definir la imaginación en contraposición a la senso-percepción. Sea como fuere, la imaginación cae del lado de lo sensible, depende menos del pensamiento que de las cosas materiales que pueden percibirse pero, sobre todo, verse:

Así, pues, si ninguna otra facultad posee las características expuestas excepto laimaginación y ésta consiste en lo dicho, la imaginación será un movimiento producido por la sensación en acto. Y como la vista es el sentido por excelencia, la palabra «imaginación» (phantasía) deriva de la palabra «luz» (pháos) puesto que no es posible ver sin luz. (429aI-5)

Habrá que esperar hasta Descartes para que la imaginación sea expulsada de modo definitivo del conocimiento: ninguna mediación es necesaria entre la res cogitans y la res extensa. En la "Meditación Sexta», Descartes se esfuerza por separar imaginación de intelección. Si imagino un triángulo, no sólo puedo concebir una figura de tres líneas y tres ángulos, sino que además contemplo la figura "con los ojos del espíritu". Es decir, la concibo y la imagino. Pero si quiero pensar un quiliógono, puedo concebir que sea una figura de mil lados, pero no puedo contemplarlo y, por lo tanto, no puedo imaginarlo (Meditaciones 58-59). Aunque la contemplación sea la del alma, Descartes sigue haciendo dependiente a la imaginación de algún tipo de apoyo sensible, así sea el de una figura mental. De este razonamiento, Descartes concluye dos cosas: que se necesita una particular contención del espíritu para ejercer la facultad de imaginar, facultad que por lo tanto se vuelve secundaria en relación con la intelección pura o intuición; que la 
facultad de imaginar, si bien está en mí, no pertenece a mi esencia, puesto que podría prescindir de ella, siendo como es dependiente de lo perceptivo.

Algunos siglos después, Sartre dirá exactamente lo contrario: de lo que se trata en la imaginación es de una cierta pobreza de cualidades, un esquematismo y reducción en contraste con la percepción (20). Con lo cual el quiliógono sí puede ser imaginado, aunque no podamos ver los mil lados con los ojos del espíritu. Sartre define la imaginación como «negación del mundo según un determinado punto de vista» (236). Esta definición es convergente con la demanda de los jóvenes del 68: negar el mundo constituido según un punto de vista que da un objeto en su ausencia. La imagen del Mayo Francés es la de la emancipación: una ausencia que se afirma como una cierta presencia.

Un poco más acá en el tiempo, y volviendo a lo que Agamben describía como expulsión de la imaginación del campo de conocimiento, dice Daniel Link: «De todas las categorías estéticas necesarias para una descripción adecuada de los movimientos estéticos del siglo xx, la imaginación es la que (salvo en Blanchot) menos atención ha recibido» (39). De modo que la marginación de la categoría se ha dado, de modo simultáneo, en la teoría del conocimiento y en la teoría del arte. Ambas marginaciones estarían vinculadas. Aunque, al nombrar a Blanchot, Link omite un nombre (el de Gaston Bachelard), es indudable que no sólo en la estética del siglo xx, sino también en la crítica (artística y literaria), la imaginación ha sido desplazada por la hegemonía del estructuralismo primero y después por el «textualismo»del posestructuralismo. Esto es, la problemática del lenguaje, la generalización de la noción de texto, sugerida por Jacques Derrida pero, como él mismo lo ha dicho, a menudo malinterpretada, ha hegemonizado los estudios literarios (pero también el análisis de todo fenómeno cultural, vuelto realidad puramente sígnica: la semiología), desplazando la categoría de experiencia, clave para pensar la de imaginación:

Existe, a nuestro entender, una clara línea que atraviesa el debate filosófico de todo el siglo veinte, y cuya importancia se insinúa con fuerza en aquella época — para hacer luego eclosión en el medio galo a partir de la posguerra- Las disputas de fondo se zanjan entre los que se esfuerzan en sostener la primacía del lenguaje y entre los que sostienen la importancia de la experiencia... (Gasquet:19)

¿Se ha producido en las últimas décadas una deflación del predominio lingüisticista y semiológico en el campo de los estudios estéticos y literarios? ¿Ha sido esta deflación complementaria de una recuperación de la categoría de experiencia y correlativa de la actualidad filosófica de pensadores pioneros de nuestro tiempo que la colocaron en el centro (siempre desplazado) de sus reflexiones (Benjamin, Blanchot, Bataille)? ¿Es posible que haya resurgido, junto con esta recuperación, un interés por la imaginación como categoría estética, con la que sólo algunos pensadores insistieron durante la consolidación del paradigma lingüisticista (Sartre, Bachelard, Blanchot)? 
En este dossier reunimos cuatro elaboraciones en torno a la pregunta por las intersecciones posibles entre imaginación y experiencia. Si bien son heterogéneas en cuanto a los materiales sobre los cuales imprimen sus recorridos y formulaciones, confluyen en algunos tramos de sus trayectos. Al producir, en dichos tramos, algunas huellas más profundas y definidas, nos envían señales de aquello que podría, eventualmente, configurar el conjunto de imágenes de este problema.

En primer lugar, estamos tentados de plantear que, de existir una imagenprínceps, común a los cuatro textos aquí reunidos, esta sería la de movimiento libre (no amarrado) de oscilación o vaivén (¡estamos en la estela de Aristóteles?). En Cueto, la oscilación es la presuposición misma de la imagen, definida como «borde inestable entre aparición y desaparición». La oscilación se dice también, en su texto, "temblor», el modo en que la desaparición aparece musicalmente, conjugando el tiempo y el espacio, retumbando para abrir, así, la experiencia de la imagen. La imagen se vive entonces como aquello que retumba, como aquello íntimo que saca de sí y empuja a la «experiencia del afuera» y por lo tanto, como aquello que no está para ser mirado sino para ser deseado. Tenemos una imagen que no es un producto o algo plasmado, sino que es, según la bella imagen de Cueto, un temblor que debe ser escuchado, porque es la música de un cuerpo.

En su lectura de la obra de Fichte, Ritvo recupera la imagen de la oscilación en la definición de la imaginación creativa. La imaginación será el modo oscilante y flotante de vincular intuición, imaginación reproductiva, entendimiento y razón. En esa oscilación que flota entre lo fijo y lo móvil, la imaginación abre un lugar en el que, sostiene Ritvo, puede reconocerse el ejercicio de la creación y de la libertad. La imaginación, como modo de articular un vínculo entre instancias dispares, será, justamente, la encargada de traducir esas mismas disparidades, en el plano del acto de aparecer de aquello que aparece, o en la dimensión de la enunciación (o, podríamos decir junto a Banega, del acontecimiento de la «puesta en escena») que es donde se batallan los conflictos, los movimientos y la dialéctica de la flotación en instancias despojadas de su fondo de identidad.

Tanto por el lado de Schwarzböck como por el de Banega, la imagen de la oscilación compromete expresamente, esto es, interpela (usando la noción psicoanalítica recuperada por Ritvo) al plexo completo de la experiencia estética, integrado por creadores, productores, críticos y espectadores/lectores. No cabe dudas de que una de las dimensiones que acarrea el problema de la imagen y la imaginación es el de la apertura de un espacio público (nos vemos obligados a hacer uso aquí de esta noción) en el que emerge algo que, con Bachelard, podríamos denominar «transubjetividad» de la experiencia estética. En efecto, fue el epistemólogo francés, recordado aquí porBanega, el que propuso construiruna fenomenología de la imaginaciónque contemplara simultáneamente la imagen creada por el poeta o el artista y la repercusión en el alma de quien ensueńa con ella, lector o espectador. En ambos casos, la imagen es creada por el «resaltar súbito del psiquismo», temblor compartido entre la multiplicidad deresonancias de la obra de arte en el espíritu y la unidad y profundidad de sus repercusiones en el alma (Bachelard:I2). 
En el escrito de Schwarzböck, así, se trabaja específicamente la oscilación problemática del «hacer hablar» y dejar callar de la imaginación sadiana y fogwilliana en el seno de un entramado histórico-político que pone en evidencia, en cada caso, el reparto entre vencedores y vencidos. La operación estética que entraña el hecho de dotar de palabra, es decir, de "hacer hablar» a aquellos que en la realidad no lo hacen, sobre el fondo de un silencio mucho más atroz, es lo que en el caso de Sade, se modula bajo la estrategia de dar la palabra a los verdugos, que en la realidad no necesitan hablar de lo que hacen y que, si lo hicieran, se referirían a ello con el lenguaje administrado de los edictos de estado. Lo que explora Schwarzböck de manera sutil e inteligente es lo que se puede producir al desplazar el eje de oscilación entre la palabra y el silencio o el decir y el callar, tal como lo experimenta Fogwill tanto en sus novelas como es sus escritos sociológicos. Allí, se trata de narrar por aquellos que en la realidad no lo hacen, los vencedores, para que hablen de cualquier cosa menos de lo que los hace poderosos, porque si lo hicieran ya no podrían comportarse como tales, ni podrían pasar su victoria como una derrota para, así, perdurar en su poder.

Tanto en Sade como en Fogwill, la tarea del lector es fundamental, ya que funciona como catalizador, en la obra de arte, del tráfico entre vencedores y vencidos y entre el hablar y el callar de regímenes de reparto de lo sensible en el que la violencia política actúa de manera silenciosa. Por la oscilación entre su idolatría edulcorada y su resistencia a la identificación (o entre Bataille y Le Brun, tal como lo piensa Schwarzböck) el lector despabilado podrá instalarse en la incomodidad de lo que Sade le hace decir a sus verdugos y de lo que calla en esa verborragia, o en esa imaginación teorética: el hecho, probado por los crímenes totalitarios, de que los poderosos o los vencedores no necesitan hablar de aquellos crímenes que, de hecho, no han cometido con sus propias manos. Ese lector también podrá, dejándose ilustrar por el silencio de los vencedores interpelados por Fogwill, reconocer que, en el pensamiento y la narración autenticada de la derrota que corresponde al vencido de la última dictadura militar argentina, es el vencedor —el poder económico que instrumentó a los verdugos - el que, callado, permanece y se regodea en todo su poder.

Por su parte, la imagen de la oscilación en Banega se fraguará a partir de la exploración husserliana de la experiencia estética aplicada a la escena teatral. En el espacio abierto entre el mundo de los objetos y cuerpos de la percepción y el mundo de la creación estética, se trama el conflicto de oscilación entre la realidad y la fantasía. Es en el seno de este conflicto que actuará la conciencia de imagen, acompañada siempre por la conciencia de distinción, que permite reconocer, en una imagen-objeto, la presencia, la ausencia, y la evocación, produciendo la autonomía relativa de la imagen artística. Gracias a esta autonomía relativa se puede llegar a concebir el goce estético del espectador, que ha decidido deliberadamente neutralizar los juicios de existencia. Aquí se recupera la noción de ficción perceptiva, que supone un pacto de neutralidad al cancelar, desde el comienzo de la representación, el conflicto entre la aprehensión perceptiva y la «aprehensión pre- 
sentificativa», esto eso, la aprehensión de los objetos físicos del mundo objetivo y la aprehensión de la escena teatral. Estaría comprometido en todo esto un acto de libertad, en el que el sujeto o espectador estético puede decidir la resolución del conflicto, «a favor de la ficción» o renegando de ella, desestimándola. En el caso de someterse a las reglas propuestas por el objeto-imagen, no buscará en él más que el goce que le prodiga su manera de presentarse, o su figuración imaginativa. El abordaje fenomenológico de la conciencia de imagen, propia de la experiencia estética, permite efectivamente considerar el goce de la imagen-objeto en el espectador de la obra de arte, en la inmanencia de la imagen y no a través de ella.

No obstante, y esto quizás es lo que Banega denomina versiones heréticas de la fenomenología husserliana, la oscilación o el conflicto no estaría resuelto de manera definitiva, y menos en el ámbito de la escena teatral contemporánea en el que, como señala el autor, se produce una constante irrupción de lo real en la ficción.

En todo caso, es justamente en el plano de la oscilante inmanencia a la que nos arroja la obra de arte que algo de la imaginación puede ser explorado, entendiendo por ella algo que, como sostiene Ritvo a partir de Fichte, se sitúa a la vez más acá y más allá del lenguaje. En este sentido, cabe concebir a la imaginación, entonces, como aquello que interpela la linealidad del tiempo e interrumpe la continuidad del espacio, en ese estado de forzada actividad que sobreviene luego de haberse «arrancado de la quietud».

La imaginación, dirá Ritvo, «está forzada a traducir, a buscar continuamente equivalentes no equivalentes para dar cuenta de una tensión dispar entre dos orillas del discurso». La traducción será aquella que tomará a su cargo la infinita y oscilante tarea de reconocer la simultaneidad y no poder alcanzarla, o de consignar lo indivisible encarnado en la conciencia mostrando, en su misma ejecución, la «imposibilidad de una síntesis clásica». En el mito de Eurídice y Orfeo, Cueto invita a imaginar la música como aquello inimaginable y que, sin embargo, es imagen en Eurídice, la desaparecida. Orfeo es sólo el que traduce esa música a canto, a sucesión, a solicitud, a deseo.

Si bien, como dice Cueto, «Nadie sabe qué hacer con una imagen», lo cierto es que la imagen y la imaginación, tal como son trabajadas aquí por nuestros escritores, hacen muchas cosas con nosotros. Eso supone que el resurgimiento del interés por la categoría de imaginación, en su gravitación oscilante y entrelazada a la de experiencia, implica no sólo la recuperación activa de toda una línea de reflexiones filosóficas y estéticas que hasta hace poco eran relativamente extrańas o poco relevantes para el mundo de la crítica, sino también la relocalización y el replanteo de un plexo de problemas asociados a ella, como el de la percepción, la conciencia, la coyuntura histórica y la comunidad. Su larga confusión con la noción de imaginario, colocada por la tradición psicoanalítica en un nivel ontológico degradado con respecto a otras dimensiones, como la de lo simbólico o lo real, contaminaba su incuestionable relevancia a la hora de interpelar la obra de arte y sus relaciones con lo político y la política. Los escritos aquí reunidos nos permiten, en su recuperación, divisar otros proyectos y otras proyecciones de la imaginación rehabilitada. 


\section{Bibliografía}

Agamben, Giorgio (2007). Infancia e historia. Destrucción de la experiencia y origen de la historia. Buenos Aires: Adriana Hidalgo.

Aristóteles (1995). Acerca del alma. Madrid: Gredos.

Bachelard, Gastón (2000). La poética del espacio. Buenos Aires: Fondo de Cultura Económica.

Badiou, Alain (2005). El siglo. Buenos Aires: Manantial.

Descartes, René (2004). Discurso del método. Meditaciones metafísicas. Buenos Aires: Terramar.

Ferrer Ortega, Jesús Guillermo (2009). «Percepción, conciencia de imagen y consideración estética en la fenomenología husserliana».RevistaEidos 10, 52-91.

Gasquet, Axel (20I4). Georges Bataille. Una teoría del exceso. México: Universidad Veracruzana.

Link, Daniel (2009). Fantasmas. Imaginación y sociedad. Buenos Aires: Eterna Cadencia.

Platón (1992). Sofista. Madrid: Gredos.

Sartre, Jean-Paul (1964). Lo imaginario. Buenos Aires: Losada, 1997. 